\title{
Bioactive constituents with antibacterial, resistance modulation, anti-biofilm formation and efflux pump inhibition properties from Aidia genipiflora stem bark
}

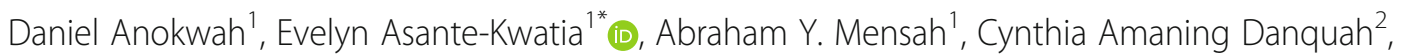
Benjamin K. Harley ${ }^{3}$, Isaac Kingsley Amponsah ${ }^{1}$ and Lukas Oberer ${ }^{4}$

\begin{abstract}
Background: Antimicrobial resistance is a global health challenge. The involvement of bacterial biofilms and efflux pumps in the development of multidrug resistance (MDR) is well established. Medicinal plants have been proposed as alternatives for combating MDR focusing on their bioactive constituents with resistance modulatory activities. This study was aimed at investigating the stem bark of Aidia genipiflora for bioactive constituents with anti-biofilm, efflux pump inhibition and resistance modulatory activities.
\end{abstract}

Method: The crude methanol extract was purified by column chromatography and isolated compounds characterized by mass and nuclear magnetic resonance spectrometry. Antibacterial activity was determined by the High-throughput spot culture growth inhibition and the broth micro-dilution assay. The ethidium bromide accumulation assay was used to determine efflux pump inhibition property. Biofilm inhibition was determined in a microplate crystal violet retention assay.

Results: Purification of the ethyl acetate fraction led to the isolation of oleanonic acid (1), 4-hydroxy cinnamic acid docosyl ester (2), $\beta$-stigmasterol/ $\beta$-sitosterol (mixture $3 \mathrm{a} / \mathrm{b}$ ) and D-mannitol (4). The minimum inhibitory concentrations (MICs) ranged from 250 to $>500 \mu \mathrm{g} / \mathrm{mL}$ for extracts and fractions and from 15 to $250 \mu \mathrm{g} / \mathrm{mL}$ for compounds. In the presence of sub-inhibitory concentrations of the compounds, the MIC of amoxicillin against $E$. coli $(20 \mu \mathrm{g} / \mathrm{mL})$ and P. aeruginosa $(320 \mu \mathrm{g} / \mathrm{mL})$ was reduced by 32 and 10 folds respectively. The whole extract demonstrated anti-biofilm formation and efflux pump inhibition in E. coli, S. aureus and P. aeruginosa. The sterol mixture (3a/b) at concentration of $100 \mu \mathrm{g} / \mathrm{mL}$ caused the highest inhibition (73\%) of biofilm formation in S. aureus. Oleanonic acid (1) demonstrated remarkable efflux pump inhibition at MIC of $7.8 \mu \mathrm{g} / \mathrm{mL}$ in E. coli better than the standard drugs verapamil and chlorpromazine.

Conclusion: This study confirms the prospects of A. genipiflora as a source of new antibacterial agents and adjuvants that could interact with some resistance mechanisms in bacteria to enhance the activity of hitherto ineffective antibiotics. "A small portion of the study has been presented in a conference in the form of poster".

Keywords: Aidia genipiflora, Biofilm, Modulation, Efflux pump, Oleanonic, Antibacterial

\footnotetext{
* Correspondence: emireku@yahoo.com

'Department of Pharmacognosy, Kwame Nkrumah University of Science and

Technology, Kumasi, Ghana

Full list of author information is available at the end of the article
}

\section{Springer Open}

(c) The Author(s). 2021 Open Access This article is licensed under a Creative Commons Attribution 4.0 International License, which permits use, sharing, adaptation, distribution and reproduction in any medium or format, as long as you give appropriate credit to the original author(s) and the source, provide a link to the Creative Commons licence, and indicate if changes were made. The images or other third party material in this article are included in the article's Creative Commons licence, unless indicated otherwise in a credit line to the material. If material is not included in the article's Creative Commons licence and your intended use is not permitted by statutory regulation or exceeds the permitted use, you will need to obtain permission directly from the copyright holder. To view a copy of this licence, visit http://creativecommons.org/licenses/by/4.0/. 


\section{Introduction}

The increasing frequency of antimicrobial resistance (AMR) has resulted in lower rates of antibiotic efficacy and hence therapeutic failure [1]. Today common infections that were hitherto easy to cure have become increasingly difficult and sometimes impossible to treat resulting in an increased morbidity and mortality from infectious diseases [2]. Coupled with this problem is the depleting pipeline of new antibiotics which has necessitated the search for new potent antimicrobial agents [3].

Among the various mechanisms of antimicrobial resistance, bacteria biofilms and efflux pumps have been shown as main contributors to AMR [4]. The over expression of efflux pumps enable bacteria to extrude broad spectrum of antibiotics to their exterior rendering the drugs ineffective [5]. Biofilm formation is a vital microbial survival strategy through which they exhibit higher resistance than planktonic forms. An enlarged gene pool, more efficient quorum sensing systems, passive resistance and metabolic cooperation are ways by which biofilm forming bacteria protect themselves from antimicrobial agents and host immune responses [6]. Research has shown that efflux pumps are highly active in bacterial biofilms making these two attractive targets for the pharmacological development of new antibacterial agents against resistant pathogens [4].

Medicinal plants are constantly faced with attack from pathogenic microorganisms in the environment, prompting them to produce a wide range of metabolites to protect themselves [7]. Studies have shown that these plant metabolites may be of clinical significance in combatting resistant bacteria due to their highly diversified chemical structures and mechanisms of action $[8,9]$. The objective of this study was to investigate the crude extract, fractions and some constituents of the stem bark of Aidia genipiflora for antimicrobial, anti-biofilm formation, efflux pump inhibition and resistance modulation activities as part of a continuing effort to identify bioactive constituents of tropical medicinal plants [10, 11].

Aidia genipiflora (DC.) Dandy (Rubiaceae) also referred to as Randia genipiflora is distributed in the wild forests of African countries including Ghana, Sierra Leone, Liberia, Nigeria, Ivory Coast, Guinea-Bissau, Sudan and Cameroon. Its leaves and stem bark are used for treating gout, oedema and boils in traditional medicine [12]. A search in literature however revealed little or no scientific investigations on it biological activity and phytochemistry, thus prompting this research.

\section{Materials and methods}

Drugs and chemicals

Amoxicillin (Phyto-Riker, Accra, Ghana); organic solvents were purchased from BDH laboratory supplies, England. Silica gel 60 (70-230 mesh, AppliChem, $\mathrm{GmbH}$, Darmstadt, Germany) and pre-coated silica gel $\mathrm{F}_{254}$ aluminium sheets (Merck kGaA, Germany).

\section{Plant material collection}

The stem bark of $A$. genipiflora was collected from Kwahu Asakraka, a town in the Eastern Region of Ghana $\left(06^{\circ} 36.704^{\prime} \mathrm{N} / 000^{\circ} 42.659^{\prime} \mathrm{W}\right)$ in November, 2018. The plant material was authenticated by a botanist, Dr. George Henry Sam of the Department of Herbal Medicine, Faculty of Pharmacy and Pharmaceutical Sciences, Kwame Nkrumah University of Science and Technology (KNUST), Kumasi, Ghana. A voucher specimen (KNUST/HM/2017/SB016) was kept at the herbarium of the Faculty.

\section{Preliminary phytochemical screening}

The presence of major secondary metabolites in the powdered stem bark of A. genipiflora was determined by simple qualitative phytochemical screening methods [13].

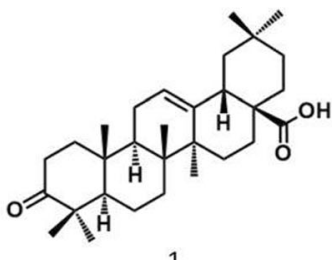

1

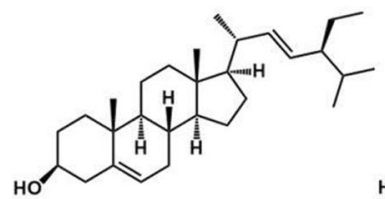

$3 a$

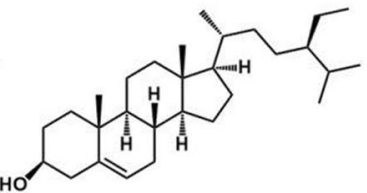

$3 b$



2<smiles>OC[C@@H](O)[C@H](O)[C@H](O)[C@H](O)CO</smiles>

4

Fig. 1 Isolated compounds from the stem bark of Aidia genipiflora 
Table 1 Phytochemical screening of the stem bark of $A$. genipiflora

\begin{tabular}{lc}
\hline Secondary metabolite & Result \\
\hline Tannins & + \\
Reducing sugars & + \\
Alkaloids & + \\
Saponins & - \\
Triterpenoids & + \\
Phytosterols & + \\
Flavonoids & + \\
Coumarins & + \\
\hline
\end{tabular}

+: detected; -: not detected

\section{Preparation of extracts and fractions}

The stem bark was washed under running water, chopped into pieces, air dried for a week and pulverized into coarse powder. Three kilograms of the powdered stem bark was extracted by Soxhlet extraction with methanol/chloroform (4:1) for $6 \mathrm{~h}$. The extract obtained was concentrated on a rotary evaporator under reduced pressure and temperature to obtain a brown solid extract subsequently referred to as AG or 'the whole extract' in this report. A yield of $5.1 \% \mathrm{w} / \mathrm{w}(153.2 \mathrm{~g})$ was obtained. The whole extract $(100 \mathrm{~g})$ was adsorbed onto silica gel 60, packed onto a glass column and eluted successively with petroleum ether $(200 \mathrm{~mL} \times 3)$, ethyl acetate $(200 \mathrm{~mL} \times 3)$ and methanol $(200 \mathrm{~mL} \times 3)$ to afford pet ether (AGPE, $4.3 \mathrm{~g}$ ), EtOAc (AGEt, $38.8 \mathrm{~g}$ ) and $\mathrm{MeOH}$ (AGM, $53.2 \mathrm{~g}$ ) fractions. The extract and fractions were kept in a dessicator until required for use.

\section{Isolation and characterization of bioactive constituents}

The ethyl acetate fraction (AGEt, $28.3 \mathrm{~g}$ ) was subjected to purification by column chromatography (CC). CC was performed using silica gel 60 (70-230 mesh). Elution was done using mixtures of pet-ether, EtOAc and

Table 2 MICs of A. genipiflora stem bark extract and fractions against clinically significant bacteria in HTSPOTi assay

\begin{tabular}{llllll}
\hline Microorganism & \multicolumn{5}{l}{ Minimum inhibitory concentration $(\boldsymbol{\mu g} / \mathbf{m L})$} \\
\cline { 2 - 6 } & AG & AGPE & AGEt & AGM & Amoxicillin \\
\hline S. aureus & $>500$ & $>500$ & $>500$ & 250 & 3.91 \\
S. pyogenes & 500 & $>500$ & $>500$ & $>500$ & 1.95 \\
E. faecalis & 500 & $>500$ & $>500$ & $>500$ & 0.49 \\
P. aeruginosa & $>500$ & $>500$ & 500 & $>500$ & 500 \\
P. mirabilis & 250 & 250 & 250 & $>500$ & 31.25 \\
K. pneumoniae & $>500$ & $>500$ & 250 & $>500$ & 31.25 \\
S. typhi & $>500$ & $>500$ & 500 & $>500$ & 62.50 \\
E. coli & 250 & $>500$ & $>500$ & $>500$ & 125 \\
V. cholerae & 500 & 500 & 500 & 500 & 125 \\
\hline
\end{tabular}

AG-whole extract, AGPE- pet ether fraction, AGEt - EtOAc fraction, AGM $\mathrm{MeOH}$ fraction
Table 3 MICs of isolated compounds from A. genipiflora stem bark extract

\begin{tabular}{lllll}
\hline Microorganism & \multicolumn{4}{c}{ Minimum inhibitory concentration $(\boldsymbol{\mu g} / \mathbf{m L})$} \\
\cline { 2 - 5 } & $\mathbf{1}$ & $\mathbf{2}$ & $\mathbf{3}$ & Amoxicillin \\
\hline S. aureus & 15.63 & 31.25 & 31.25 & 10 \\
E. faecalis & 15.63 & 31.25 & 31.25 & 10 \\
E. coli & 15.63 & 125 & 125 & 20 \\
P. aeruginosa & 15.63 & 250 & 125 & $>320$ \\
\hline
\end{tabular}

$\mathrm{MeOH}$ by gradient elution. Thin layer chromatography (TLC) was done using pre-coated silica gel 60 TLC plates (GF254 $0.25 \mathrm{~mm}$, Alpha laboratories, UK). Three pure compounds and one phytosterol mixture were isolated (Fig. 1). Characterization of the compounds was achieved by comparing their ${ }^{1} \mathrm{H},{ }^{13} \mathrm{C}$ NMR and mass spectral data with published data. Details of the isolation procedure are presented in supplementary material (See Additional File 1).

\section{Antimicrobial testing}

Bacterial strains and inoculum standardization

Clinical and American type culture collection (ATCC) bacteria strains were provided by the cell culture laboratory of the Department of Pharmacology, KNUST. They included Gram-positive bacteria: Staphylococcus aureus ATCC 25923, Enterococcus faecalis ATCC 29212, Streptococcus pyogenes- clinical strain and Gramnegative bacteria: Pseudomonas aeruginosa ATCC 27853, Proteus mirabilis ATCC 12453, Kleibsiella pneumoniae-clinical strain, Salmonella typhi-clinical strain, Escherichia coli ATCC 25922 and Vibrio cholerae-clinical strain.

A standardized bacteria culture was prepared from overnight cultures (prepared by inoculating sterile nutrient broth with test organism and incubating at $37^{\circ} \mathrm{C}$ for $24 \mathrm{~h})$. The organisms were then collected and standardized by serial dilution in sterile normal saline to achieve an initial cell count of approximately $1 \times 10^{5} \mathrm{CFU} / \mathrm{mL}$.

\section{Evaluation of antibacterial activity of crude extracts and fractions}

The antibacterial activity of the whole extract and major fractions was tested by the high-throughput spot culture growth inhibition assay (HT-SPOTi) as previously described [14]. Amoxicillin was included as the positive control and 2\% DMSO, negative control. The experiment was performed in triplicate.

\section{Determination of the antibacterial activity and antibiotic modulation effect of compounds}

The MIC of isolated compounds against two WHO high priority (S. aureus and E. faecalis) and WHO critical priority organisms ( $P$. aeruginosa and $E$. coli) was 
Table 4 Minimum inhibitory concentration (MIC) of Amoxicillin in the absence or presence of compounds at $1 / 4$ MIC concentration

\begin{tabular}{|c|c|c|c|c|c|c|c|c|}
\hline & Minimu & itory Conc & $\mathrm{n}(\mu \mathrm{g} / \mathrm{mL})$ & & & & & \\
\hline & P. aerug & & & & E. coli & & & \\
\hline & MIC & MIC com & & & MIC & MIC com & & \\
\hline & Amox & 1 & 2 & 3 & Amox & 1 & 2 & 3 \\
\hline & $>320$ & $<31.25$ & $<31.25$ & $<31.25$ & 20 & $<0.625$ & 0.625 & 0.625 \\
\hline$\overline{\mathrm{MF}}$ & & $<10$ & $<10$ & $<10$ & & $<32$ & 32 & 32 \\
\hline
\end{tabular}

MF: Modulation factor, Amox-Amoxicillin

determined by the broth dilution method as previously described by Cos, 2006 [15]. Amoxicillin was included as positive control and $2 \%$ DMSO as negative control.

For the modulation test, the MIC of amoxicillin was determined in the absence or presence of the isolated compounds against $P$. aeruginosa and $E$. coli using the broth dilution assay as previously described [16]. The modulation factor (MF) was used to express the modulation effect of the compound on the MIC of amoxicillin and was calculated as the ratio of the MIC of the antibiotic alone and the MIC of antibiotic in the presence of compounds.

\section{Biofilm inhibition assay}

The effect of the crude extract and isolated compounds on biofilm formation by $S$. aureus, E. coli and $P$. aeruginosa was investigated using the microplate crystal violet stain retention method as previously described [17]. As controls, wells containing only medium without test samples were included. The experiment was performed in triplicate.

\section{Ethidium bromide (EtBr) accumulation assay (efflux pump inhibition assay)}

The crude extract and isolated compounds were investigated for their ability to enhance the accumulation of EtBr (a substrate for efflux pumps) into bacterial cells according to a previously described method [16]. The known efflux pump inhibitors (EPI) verapamil and chlorpromazine were included as comparative probes and DMSO as the negative control. The experiment was performed in triplicate.

\section{Data management and analysis}

All experimental results were analyzed using Graph Pad Prism (Version 5 for windows, San Diego, USA).

\section{Results}

Preliminary phytochemical investigation of the stem bark of A. genipiflora

The result of preliminary phytochemical screening performed on the dried powdered stem bark of A. genipiflora revealed the presence of some classes of plant secondary metabolites as presented on Table 1.

Isolated compounds from the stem bark of $A$. genipiflora Chromatographic fractionation and purification of the bioactive EtOAc fraction resulted in the isolation of five known compounds identified based on their ${ }^{1} \mathrm{H}$ and ${ }^{13} \mathrm{C}$ NMR data. All spectral and physicochemical data obtained for the compounds matched those reported in literature for oleanonic acid (1) [18], 4-hydroxy cinnamic acid docosyl ester (2) [19], $\beta$-stigmasterol and $\beta$ sitosterol (3a/3b; 2:3) [20] and D-mannitol (4) [21] (Fig. $1)$. These compounds are known to occur in several





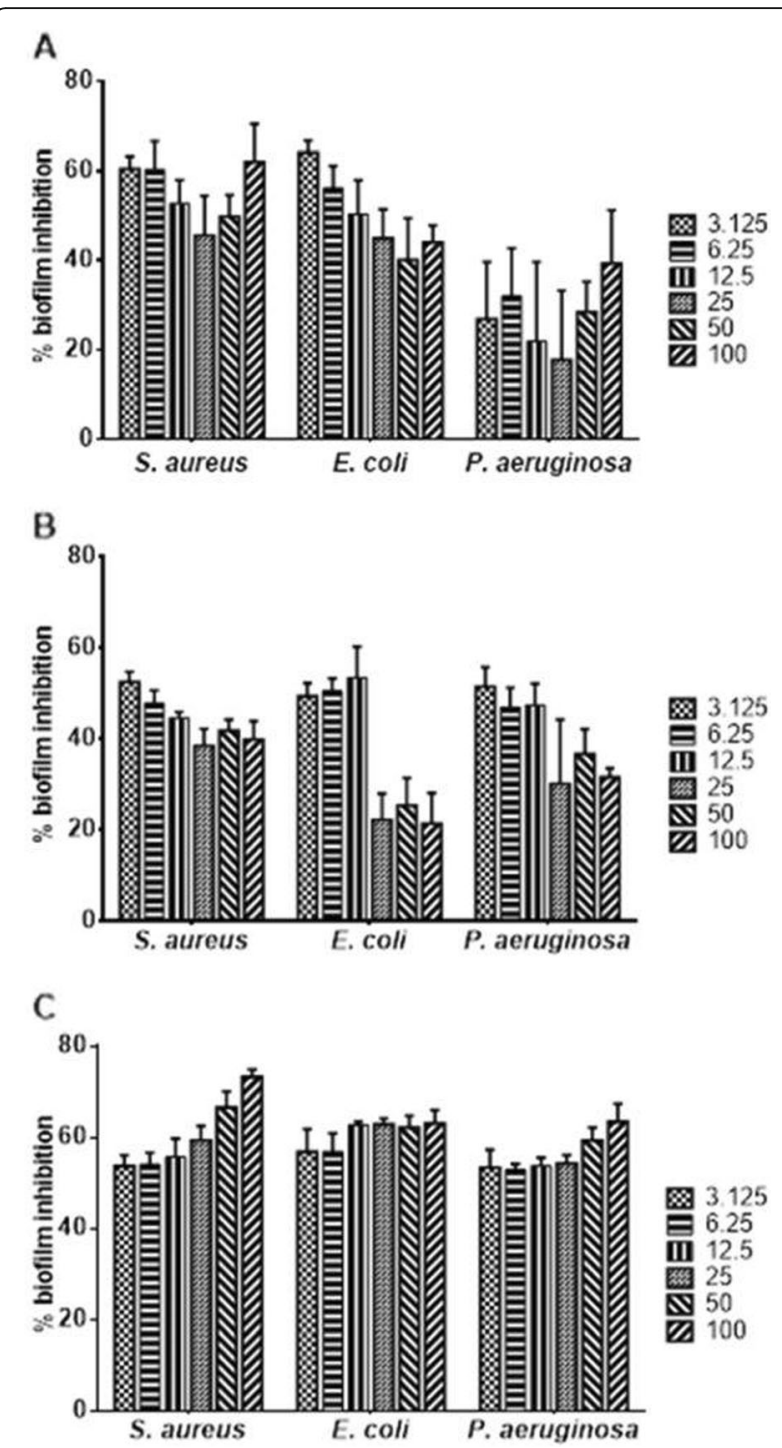

Fig. 3 Anti-biofilm formation effect of compounds $\mathbf{1 - 3}(A-C)$ in $S$. aureus, E. coli and P. aeruginosa

plant species but are being reported for the first time from A. genipiflora. The spectral data of the compounds have been provided in the supplementary material (See Additional File 1).

\section{Antibacterial activity of $A$. genipiflora stem bark extract and major fractions}

The whole extract, $\mathrm{MeOH}, \mathrm{EtOAc}$ and pet-ether fractions exhibited varying degrees of growth inhibition towards Gam-positive and Gram-negative bacteria in the HTSPOTi assay. For susceptible bacteria, the MIC ranged between 250 and $500 \mu \mathrm{g} / \mathrm{mL}$ and varied with respect to the different bacteria and solvent extract (Table 2). P. mirabilis was the most susceptible organism being inhibited at $250 \mu \mathrm{g} / \mathrm{mL}$ by most extracts. Amoxicillin had variable inhibitory activities depending on the organisms tested with the highest inhibitory effect $(\mathrm{MIC}<10 \mu \mathrm{g} / \mathrm{mL}$ ) against the Gram positive bacteria i.e. S. aureus, $S$. pyogens and $E$. faecalis. $P$. aeruginosa was the least susceptible to amoxicillin.

\section{Antimicrobial activity and resistance modulation effect of isolated compounds}

The antimicrobial activity of the isolated compounds was investigated against $S$. aureus, $P$. aeruginosa, E. coli and E. faecalis (WHO high priority and critical priority organisms, WHO, 2019) in the broth dilution assay. The minimum inhibitory concentrations are presented on Table 3. All compounds demonstrated antibacterial activity at MIC range between 15 and $250 \mu \mathrm{g} / \mathrm{mL}$ (Table 3 ). Compound 1 demonstrated the highest inhibitory effect against the test organisms at MIC $15.6 \mu \mathrm{g} / \mathrm{mL}$. Compounds $\mathbf{2}$ and $\mathbf{3}$ showed varying inhibitory effects against the organisms with the Gram negative bacteria being less susceptible (MIC: $125-250 \mu \mathrm{g} / \mathrm{mL}$ ) than the Gram positive (MIC: $31.25 \mu \mathrm{g} / \mathrm{mL}$ ).

The isolated compounds at sub-inhibitory concentrations $(1 / 4 \mathrm{MIC})$ were investigated for antibacterial resistance modulatory effect in amoxicillin against $E$. coli and $P$. aeruginosa. From the results, all compounds when coadministered with amoxicillin notably potentiated its antibacterial activity against $P$. aeruginosa and E. coli (Table 4). The MIC of amoxicillin in the presence of the isolated compounds was reduced from 320 to $31.25 \mu \mathrm{g} /$ $\mathrm{mL}$ i.e. modulation factor (MF) of 10 for P. aeruginosa. In E. coli, the MIC of amoxicillin was reduced from 20 to $0.625 \mu \mathrm{g} / \mathrm{mL}$ i.e. $\mathrm{MF}=32$.

\section{Biofilm formation inhibitory effect of $A$. genipiflora stem bark extract and isolated compounds}

The whole extract of A. genipiflora stem bark (AG) was investigated for biofilm formation inhibitory effect against $S$. aureus, E. coli and $P$. aeruginosa in the crystal violet retention assay. The extract exhibited remarkable concentration-dependent inhibition of biofilm formation between $15.6-500 \mu \mathrm{g} / \mathrm{mL}$. The highest anti-biofilm formation effect was expressed against $E$. coli followed by $S$. aureus then $P$. aeruginosa (Fig. 2). The percentage biofilm inhibition against $E$. coli at its sub-inhibitory concentration $(15-125 \mu \mathrm{g} / \mathrm{mL})$ ranged between 60 and $79 \%$. For $S$. aureus and P. aeruginosa, the percentage biofilm inhibition ranged between 60 and $76 \%$ and $3-57 \%$ respectively at sub-inhibitory concentration of $15-500 \mu \mathrm{g} /$ $\mathrm{mL}$.

The effect of compounds $\mathbf{1}, \mathbf{2}$ and $\mathbf{3 a} / \mathbf{b}(3.1-100 \mu \mathrm{g} /$ $\mathrm{mL}$ ) on biofilm formation in S. aureus, E. coli and P. aeruginosa is presented on Fig. 3. The highest inhibition of biofilm formation was given by compound $\mathbf{3 a} / \mathbf{b}$ against S. aureus (73\% inhibition) in a concentration-dependent manner. The percentage biofilm inhibition for the other 

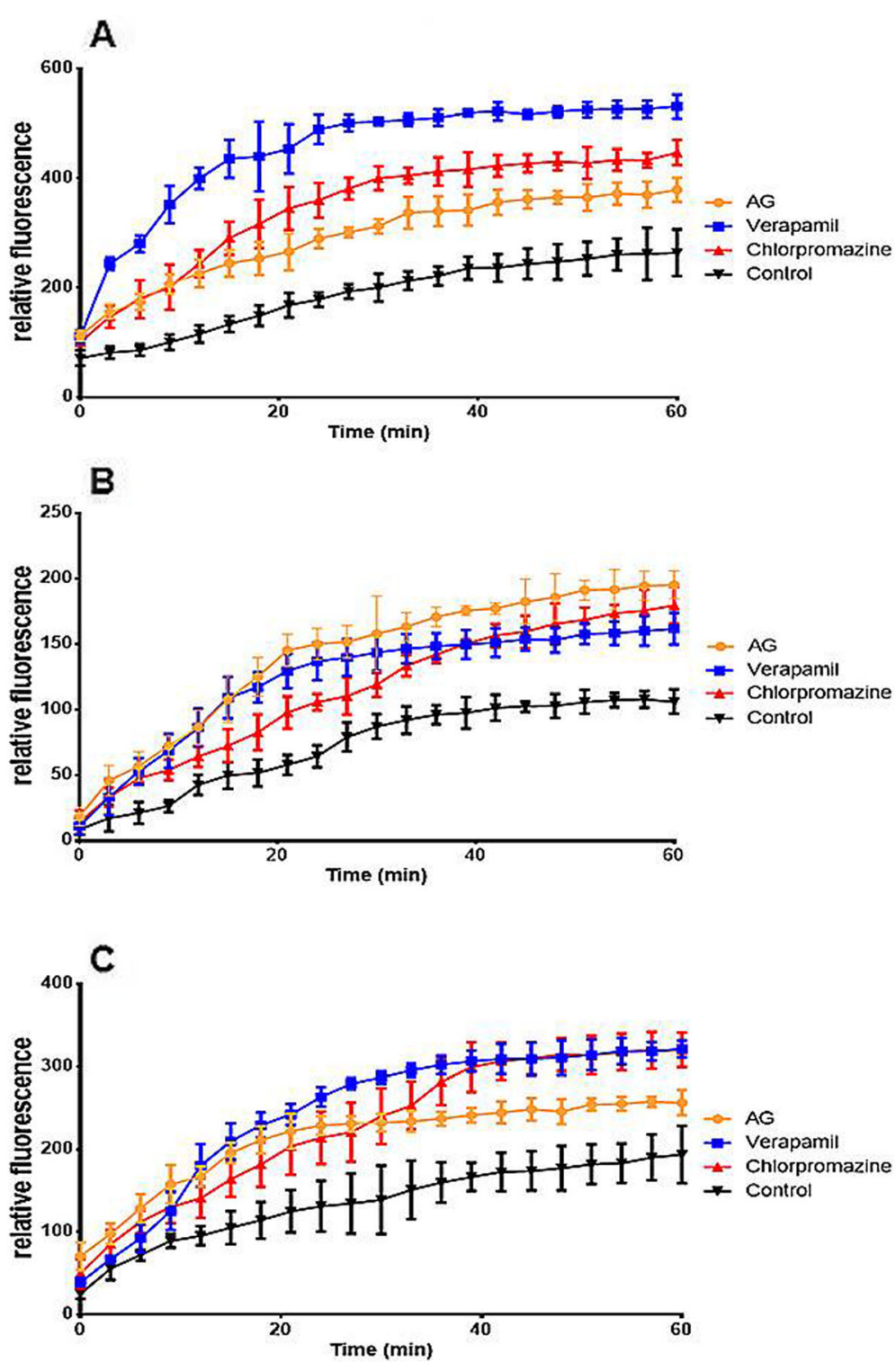

Fig. 4 Efflux pump inhibition effect of AG $(1 / 2 \mathrm{MIC})$ in S. aureus (A), E. coli (B), P. aeruginosa (C)

compounds against the test organisms ranged between 17 and $66 \%$ and was not concentration dependent. $P$. aeruginosa was the least susceptible to all test compounds.

Effect of A. genipiflora stem bark extract and isolated compounds on ethidium bromide (EtBr) accumulation in bacterial cells

The potential of the crude extract (AG) and isolated compounds $(\mathbf{1}, \mathbf{2}, \mathbf{3})$ to act as efflux pump inhibitors was investigated by the $\mathrm{EtBr}$ accumulation assay. EtBr, a substrate for several multidrug resistant efflux pumps, emits a strong fluorescent signal when bound to DNA intracellularly and only has a weak signal when present extracellularly. Thus, the activity of putative EPIs can be measured fluorometrically due to the retention of fluorescence overtime if efflux is reduced [22].

Figure 4 shows the EtBr accumulation behaviour in $S$. aureus, E. coli and P. aeruginosa in the presence of the extract (AG) compared to the action of two standard EPIs, verapamil (VP) and chlorpromazine (CP) measured over 60 mins. From the results it can be inferred that in E. coli, the crude extract (AG) exhibited remarkable efflux pump inhibition resulting in much higher EtBr fluorescence than both standard EPIs (Fig. 4b). However, in S. aureus and $P$. aeruginosa, the standard EPIs proved much effective in causing higher accumulation of EtBr in the bacterial cells than the test extract (Fig. $4 \mathrm{a}$ and c respectively).

Figure 5 shows the EtBr accumulation behaviour in $E$. coli in the presence of isolated compounds. Compound 

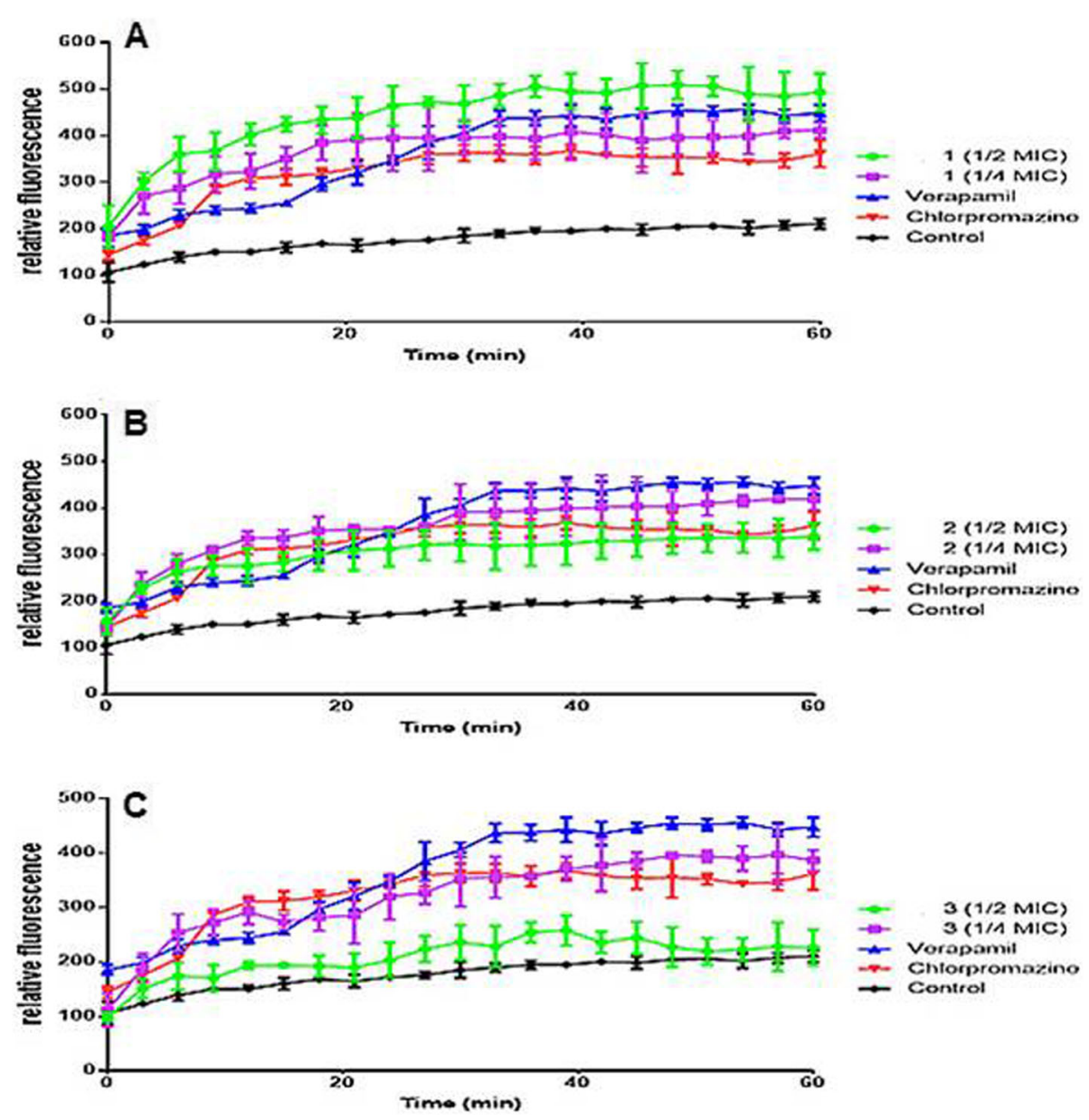

Fig. 5 Efflux pump inhibition effect of compounds $\mathbf{1 - 3}(A-C)$ in E. coli

1 at $1 / 2$ MIC showed a superior $\mathrm{EtBr}$ accumulation than both VP and CP. At $1 / 4$ MIC however, its effect was higher than CP but lower than VP (Fig. 5a). For compound 2, EtBr accumulation was higher at $1 / 4 \mathrm{MIC}$ than $1 / 2$ MIC. VP was superior to compound 2 at all concentrations tested. At $1 / 4 \mathrm{MIC}$, compound 2 showed a higher effect than CP but lower than VP. At $1 / 2$ MIC however its effect was similar to that of CP (Fig. 5b). Compound 3 at $1 / 2$ MIC showed little or no effect on EtBr accumulation activity as its effect was similar to the negative control. At $1 / 4$ MIC however, it showed a better potential to accumulate $\mathrm{EtBr}$ than $\mathrm{CP}$ but lower than VP (Fig. 5c).

The EtBr accumulation enhancement behaviour of compounds $\mathbf{1}, \mathbf{2}$, and $\mathbf{3}$ in $P$. aeruginosa is demonstrated in Fig. 6. Compound 1 at $1 / 2$ MIC enhanced accumulation of EtBr slightly higher than CP but lower than VP. At $1 / 4 \mathrm{MIC}$, its effect was lower than both $\mathrm{VP}$ and $\mathrm{CP}$ (Fig. 6a). Compounds 2 and 3 at the test concentrations showed no obvious increase on the accumulation of $\mathrm{EtBr}$ in P. aeruginosa over $60 \mathrm{~min}$ (Fig. $6 \mathrm{~b}$ and c).

\section{Discussion}

This study investigated the antimicrobial activity of $A$. genipiflora stem bark extract $\left(\mathrm{MeOH} / \mathrm{CHCl}_{3}\right)$, three solvent fractions (i.e. pet-ether, EtOAc and $\mathrm{MeOH}$ fractions) and some isolated constituents. The effect of the whole extract and isolated compounds on bacteria biofilm formation and efflux-pump inhibition as well as resistance modulation potential of isolated compounds on the antibacterial activity of amoxicillin was also evaluated.

Preliminary phytochemical studies revealed the presence of classes of secondary metabolites (Table 1) that exhibit a wide range of biological activities including antimicrobial, anti-inflammatory and antioxidant effects [23] supporting the use of the plant in traditional medicine. Other Aidia species were reported to contain coumarins, phenolic acids (catechol) and fatty acid esters [24]. From antibacterial screening of the whole extract and fractions, the MIC ranged from 250 to $>500 \mu \mathrm{g} / \mathrm{mL}$. In general, the extract and fractions had quite high MICs for most of the organisms tested (MIC $\geq 500$ ). 

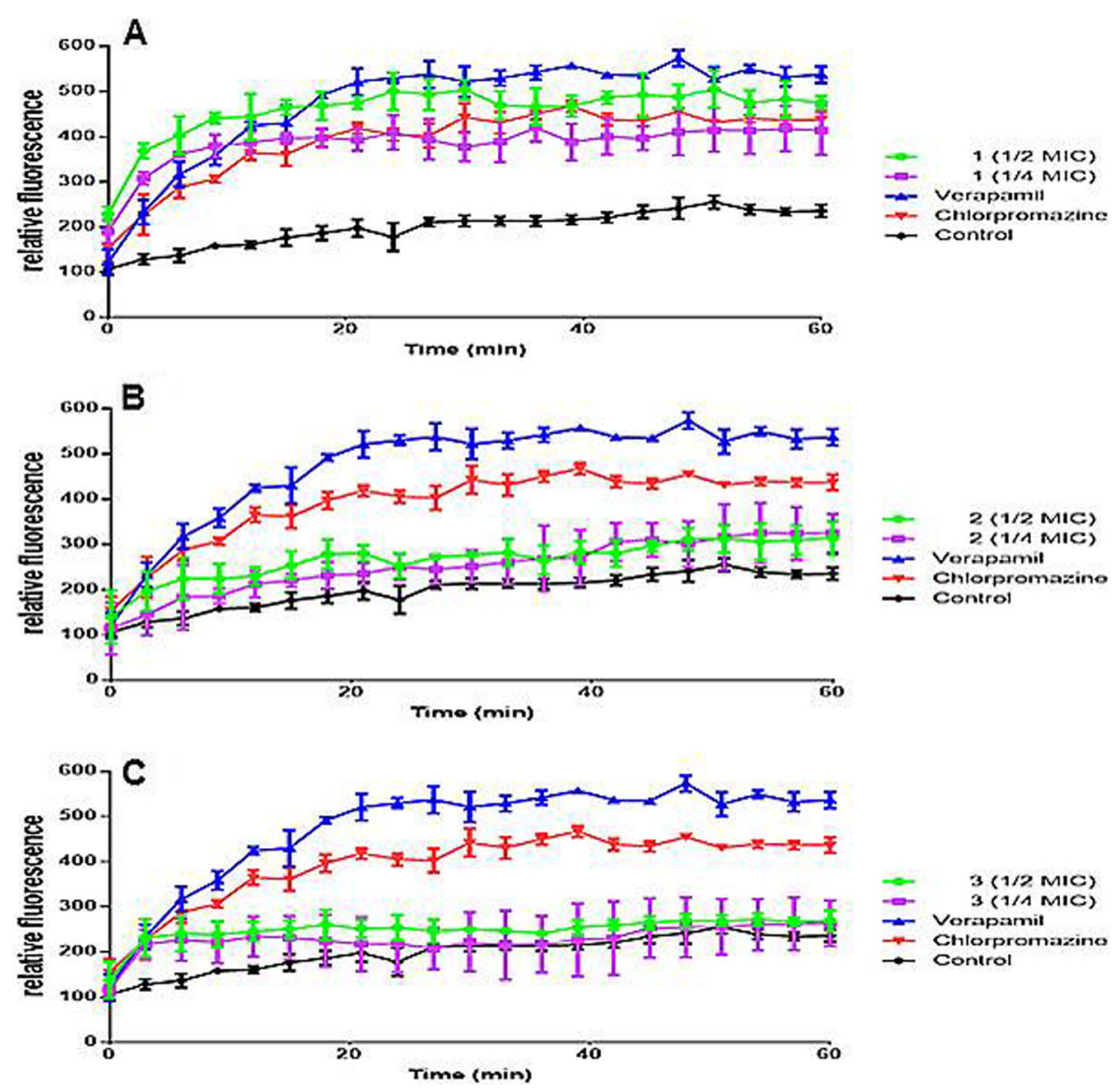

Fig. 6 Efflux pump inhibition effect of compounds 1-3 (A-C) in P. aeruginosa

Nevertheless, the antibacterial activity observed for AG, AGPE and AGEt towards P. mirabilis (MIC $=250 \mu \mathrm{g}$ / $\mathrm{mL})$, AG towards E. coli $(\mathrm{MIC}=250 \mu \mathrm{g} / \mathrm{mL})$, AGET towards $K$. pneumonia $(\mathrm{MIC}=250 \mu \mathrm{g} / \mathrm{mL})$ and AGM towards $S$. aureus $(\mathrm{MIC}=250 \mu \mathrm{g} / \mathrm{mL}$ ) are notable (Table $2)$. The antimicrobial activity of plant extracts can be classified as significant (MIC $<100 \mu \mathrm{g} / \mathrm{mL}$ ), moderate $(100 \leq \mathrm{MIC} \leq 625 \mu \mathrm{g} / \mathrm{mL})$ or weak (MIC $>625 \mu \mathrm{g} / \mathrm{mL})$ [25]. By this criterion, the whole extract and fractions can be said to have demonstrated moderate antibacterial activity. In the genus Aidia, antibacterial activity against B. subtilis, E. coli, P. aeruginosa and $S$. aureus was reported for the $\mathrm{MeOH}$ and aqueous extracts of the leaf of Aidia boorneensis [24].

Detailed phytochemical investigation led to the isolation of oleanonic acid (1) [18], 4-hydroxy cinnamic acid docosyl ester (2) [19], $\beta$-stigmasterol and $\beta$-sitosterol (3a/3b; 2:1) [20] and D-mannitol (4) [21] (Fig. 1). These compounds are known to occur in several plant species but are being reported for the first time from A. genipiflora. All compounds demonstrated antibacterial activity at MIC range between 15 and $250 \mu \mathrm{g} / \mathrm{mL}$ (Table 3). The MICs of isolated compounds being lower than the parent fraction implies that fractionation led to more active samples. For pure compounds, antimicrobial activity may be classified as significant (MIC $<10 \mu \mathrm{g} / \mathrm{mL}$ ), moderate $(10 \leq \mathrm{MIC} \leq 100 \mu \mathrm{g} / \mathrm{mL})$ or weak (MIC $>100 \mu \mathrm{g} /$ $\mathrm{mL})[25,26]$. Though none of the compounds had MIC $<10 \mu \mathrm{g} / \mathrm{mL}$, the antibacterial activity of compound $\mathbf{1}$ against all organisms (MIC $15.6 \mu \mathrm{g} / \mathrm{mL}$ ) and compounds 2 and $3 \mathbf{a} / \mathbf{b}$ against $S$. aureus and $E$. faecalis $(\mathrm{MIC}=$ $31.25 \mu \mathrm{g} / \mathrm{mL}$ ) are remarkable. In previous studies, oleanonic acid (1) demonstrated significant antibacterial activity against pathogenic Gram positive and Gram negative bacteria at MIC range between 10 and $50 \mu \mathrm{g} /$ $\mathrm{mL}$ [27] and against methicillin resistant $S$. aureus (MRSA) at $10 \mu \mathrm{g} / \mathrm{mL}$ [28]. The anti-tubercular activity of oleanonic acid (1) against Mycobacterium tuberculosis was previously reported [18]. $\beta$-stigmasterol and $\beta$ sitosterol $(\mathbf{3 a} / \mathbf{b})$ have demonstrated broad spectrum antibacterial activity against several pathogenic bacteria in previous studies [29-32]. This is the first report on the antibacterial activity of 4-hydroxy cinnamic acid docosyl ester (2) though some cinnamic acid derivatives have been shown to possess very potent antibacterial activity [33]. The presence of these compounds in $A$. 
genipiflora may thus contribute to its antibacterial activity. In modulatory tests, the MIC of amoxicillin in the presence of the isolated compounds was reduced by 10 folds for P. aeruginosa and 32 folds in E. coli. This suggests that the isolated compounds have the ability to potentiate the antibacterial effect of amoxicillin against these Gram negative bacteria. In previous studies, oleanolic acid, the parent derivative of compound $\mathbf{1}$ was found to synergistically potentiate the antibacterial activity of ampicillin and oxacillin towards S. aureus, P. aeruginosa, L. monocytogenes, S. epidermidis [34]. A combination of stigmasterol (3a) and ampicillin resulted in a significant increase in the effect of ampicillin against clinical isolates of $S$. aureus, E. coli, P. aeruginosa and $S$. pyogens [35]. The synergistic action of plant-derived compounds and antibiotics has been proposed to be by the interaction of these agents with bacterial resistance mechanisms [36] such as destruction of the bacterial membrane structure, increasing the influx of antibiotics into the bacteria cell [37] inhibition of bacterial efflux pumps, inhibition of quorum sensing and some gene expression modulations [22, 38].

The whole extract and isolated compounds further showed remarkable inhibition of biofilm formation in $S$. aureus, E. coli and P. aeruginosa. Several plant extracts and plant derived compounds have been shown to prevent the adhesion or implantation of planktonic forms of bacterial cells on abiotic surfaces thus inhibiting the formation of biofilms [39-41]. Though this is the first report on the anti-biofilm formation potential of $A$. genipiflora and its constituents, previous studies have reported the biofilm inhibitory activity of similar bioactive constituents. Cinnamic acid derivatives of natural origin exhibited significant quorum sensing and biofilm inhibition in Chromobacerim violaceum increasing its susceptibility to tobramycin [42]. Pentacyclic triterpenes and some sterols including $\beta$ - sitosterol (3b) also demonstrated remarkable anti-biofilm activities [43, 44]. Extract and plant derived compounds may inhibit biofilm formation by damaging microbial membrane structures, inhibiting peptidoglycan synthesis [45], inhibition of nucleic acid synthesis [46], quorum sensing inhibition or disruption [47] and anti-cell-adhesion properties [48].

The whole extract demonstrated potential to inhibit efflux pumps in E. coli and to a lesser extent in S. aureus and $P$. aeruginosa. For pure compounds as well, efflux ump inhibition was higher in $E$. coli than $P$. aeruginosa. It was also interesting to note that lower concentrations (1/4 MIC) of compounds 2 and 3 exhibited far greater EPI activity in $E$. coli than more concentrated samples $(1 / 2$ MIC) (Figs. 5 and 6). This observation is consistent with a previous reports on the EPI activity of some Berberis spp [49] which was attributed to the possibility of putative EPIs binding at only high affinity sites of the efflux pump causing greater inhibition at only low concentrations whereas higher concentrations would result in low affinity binding sites being occupied.

The antibacterial activity demonstrated by $A$. genipiflora and its constituents in this study has revealed the prospects of this plant as a potential source of new antibacterial agents and adjuvants that could possibly interact with some resistance mechanisms in bacteria to enhance the activity of antibiotics that have been rendered inactive by resistant organisms.

\section{Conclusion}

This study has provided the first evidence of the antimicrobial, resistance modulation, anti-biofilm formation and efflux pump inhibitory potentials of A. genipiflora stem bark and its constituents. This gives scientific credence to the traditional uses of the stem bark of A. genipiflora for managing infections. Although oleanonic acid, $\beta$-stigmasterol, $\beta$-sitosterol, 4-hydroxy cinnamic acid docosyl ester and D-mannitol are known plant bioactive compounds, this is the first report of their isolation from A. genipiflora as well as the genus, Aidia.

"A small portion of the study has been presented in a conference in the form of poster [50]"

\section{Abbreviations}

AG: A. genipiflora stem bark whole extract; AGPE: A. genipiflora stem bark pet ether fraction; AGEt: A. genipiflora stem bark ethyl acetate fraction; AGM: A. genipiflora stem bark methanol fraction; AMR: Antimicrobial resistance; AMOX: Amoxicillin; ATCC: American type culture collection; CC: Column chromatography; CFU: Colony forming unit; $\mathrm{CHCl}_{3}$ : Chloroform; CP: Chloprommazine; CV: Crystal violet; DMSO: Dimethyl sulfoxide; HTSPOTi: High throughput spot culture growth inhibition; EtBr: Ethidium bromide; EtOAc: Ethyl acetate; MeOH: Methanol; MIC: Minimum inhibitory concentration; MF: Modulation factor; MTT: 3-(4,5-Dimethylthiazol-2-YI)-2,5Diphenyltetrazolium Bromide; NMR: Nuclear magnetic resonance; PCR: Polymerase chain reaction; TLC: Thin layer chromatography; VP: Verapamil

\section{Supplementary Information}

The online version contains supplementary material available at https://doi. org/10.1186/s40816-021-00266-4.

Additional file 1. Methods of isolation of compounds and spectroscopic data of isolated compounds from Aidia genipiflora stem bark.

\footnotetext{
Acknowledgements

The authors appreciate Mr. Clifford Asare for his assistance in the plant collection and the technicians in the Department of Pharmacognosy, Pharmacology and Microbiology of the Faculty of Pharmacy and Pharmaceutical Sciences, KNUST, Kumasi. We also appreciate Thomas Allmendinger of Novartis Pharma AG, Switzerland for his assistance in accessing the NMR equipment.
}

\section{Authors' contributions}

DA and AYM developed the idea and designed the study. DA, CAD and IKA performed antimicrobial studies and analysis of results. DA and EAK carried out chromatographic studies and were major contributors in writing 
manuscript. BKH and LO were responsible for the structural elucidation of the compounds. All authors read and approved the manuscript.

\section{Funding}

This work did not receive any funding from an external source.

\section{Availability of data and materials}

The dataset supporting the conclusions of this article are included within the article and its additional files. Raw data sets used and analysed during the study are available from the corresponding author on reasonable request.

\section{Ethics approval and consent to participate}

Not applicable.

\section{Consent for publication}

Not applicable.

\section{Competing interests}

Authors have no conflict of interest to declare.

\section{Author details}

'Department of Pharmacognosy, Kwame Nkrumah University of Science and Technology, Kumasi, Ghana. ${ }^{2}$ Department of Pharmacology, Kwame Nkrumah University of Science and Technology, Kumasi, Ghana. ${ }^{3}$ Department of Pharmacognosy and Herbal Medicine, School of Pharmacy, University of Health and Allied Sciences, Ho, Ghana. ${ }^{4}$ Novartis Institutes for BioMedical Research, Basel, Switzerland.

\section{Received: 14 October 2020 Accepted: 26 February 2021}

\section{Published online: 05 March 2021}

\section{References}

1. Seukep AJ, Kuete V, Nahar L, Sarker SD, Guo M. Plant-derived secondary metabolites as the main source of efflux pump inhibitors and methods for identification. J Pharm Anal. 2019.

2. Laukkanen MO. Return of communicable diseases as a result of antibiotic resistance. Antioxid Redox Signal. 2020.

3. Igarashi M. New natural products to meet the antibiotic crisis: a personal journey. JAntibiot. 2019:1-9.

4. Kvist M, Hancock V, Klemm P. Inactivation of efflux pumps abolishes bacterial biofilm formation. Appl Environ Microbiol. 2008;74:7376-82.

5. Touani FK, Seukep AJ, Djeussi DE, Fankam AG, Noumedem JA, Kuete V. Antibiotic-potentiation activities of four Cameroonian dietary plants against multidrug-resistant gram-negative bacteria expressing efflux pumps. BMC Complement Altern Med. 2014;14:258

6. Wolcott R, Costerton J, Raoult D, Cutler S. The polymicrobial nature of biofilm infection. Clin Microbiol Infect. 2013;19:107-12.

7. Isah T. Stress and defense responses in plant secondary metabolites production. Biol Res. 2019;52:39.

8. Cowan MM. Plant products as antimicrobial agents. Clin Microbiol Rev. 1999;12:564-82.

9. van Wyk AS, Prinsloo G. Health, safety and quality concerns of plant-based traditional medicines and herbal remedies. S Afr J Bot. 2020;133:54-62.

10. Baah MK, Mensah AY, Asante-Kwatia E, Amponsah IK, Forkuo AD, Harley BK, et al. In vivo antiplasmodial activity of different solvent extracts of Myrianthus libericus stem bark and its constituents in Plasmodium bergheiinfected mice. ECAM.2020;2020.

11. Mireku EA, Kusari S, Eckelmann D, Mensah AY, Talontsi FM, Spiteller M. Antiinflammatory tirucallane triterpenoids from Anopyxis klaineana Pierre (Engl. ),(Rhizophoraceae). Fitoterapia. 2015;106:84-91.

12. Burkill $H$. The useful plants of West Africa, families M-R. Royal Botanical Gardens, Kew 1985;4.

13. Evans WC. Trease and Evans' Pharmacognosy E-book: Elsevier health sciences; 2009

14. Danquah CA, Maitra A, Gibbons S, Faull J, Bhakta S. HT-SPOTi: A Rapid Drug Susceptibility Test (DST) to Evaluate Antibiotic Resistance Profiles and Novel Chemicals for Anti-Infective Drug Discovery. Curr Protoc Microbiol. 2016;17: $1-8$.

15. $\operatorname{Cos} P$, Vlietinck AJ, Berghe DV, Maes L. Anti-infective potential of natural products: how to develop a stronger in vitro 'proof-of-concept'. J Ethnopharmacol. 2006;106:290-302.
16. Prasch S, Duran AG, Chinchilla N, Molinillo JM, Macías FA, Bucar F Resistance modulatory and efflux-inhibitory activities of capsaicinoids and capsinoids. Bioorg Chem. 2019;82:378-84

17. Abidi SH, Ahmed K, Sherwani SK, Bibi N, Kazmi SU. Detection of Mycobacterium smegmatis biofilm and its control by natural agents. Int J Curr Microbiol App Sci. 2014:3:801-12.

18. Caldwell CG, Franzblau SG, Suarez E, Timmermann BN. Oleanane triterpenes from Junellia tridens. J Nat Prod. 2000;63:1611-4.

19. Kuo YH, Lo JM, Chan YF. Cytotoxic components from the leaves of Schefflera taiwaniana. J Chin Chem Soc. 2002;49:427-31.

20. Cayme J-MC, Ragasa CY. Structure elucidation of $\beta$-stigmasterol and $\beta$ sitosterol from Sesbania grandifora [Linn.] Pers. and $\beta$-carotene from Heliotropium indicum Linn. By NMR spectroscopy. Kimika. 2004;20:5-12.

21. Branco A, Santos JDG, Pimentel MM, Osuna JT, Lima LS, David JM. D-Mannitol from Agave sisalana biomass waste. Ind Crop Prod. 2010;32:507-10.

22. Stavri M, Piddock $\amalg$, Gibbons S. Bacterial efflux pump inhibitors from natural sources. J Antimicrob Chemother. 2007:59:1247-60.

23. Kabera JN, Semana E, Mussa AR, He X. Plant secondary metabolites: biosynthesis, classification, function and pharmacological properties. J Pharm Pharmacol. 2014;2:377-92.

24. Awang-Jamil Z, Basri AM, Ahmad N, Taha H. Phytochemical analysis, antimicrobial and antioxidant activities of Aidia borneensis leaf extracts. Appl Biol Biot. 2019;7:92-7.

25. Kuete V. Potential of Cameroonian plants and derived products against microbial infections: a review. Planta Med. 2010;76:1479-91.

26. Efferth T, Kuete V. Cameroonian medicinal plants: pharmacology and derived natural products. Front Pharmacol. 2010;1:123.

27. Sharifi MS, Hazell SL. Isolation, analysis and antimicrobial activity of the acidic fractions of mastic, Kurdica, Mutica and Cabolica gums from genus Pistacia Glob J Health Sci. 2012:4:217.

28. Sharifi MS. Antimicrobial activities of triterpenoids against methicillinresistant Staphylococcus aureus (MRSA). Worldwide Research Efforts in the Fighting Against Microbial Pathogens 2013;9:51.

29. Ododo MM, Choudhury MK, Dekebo AH. Structure elucidation of $\beta$ sitosterol with antibacterial activity from the root bark of Malva parviflora. SpringerPlus. 2016:5:1-11.

30. Doğan A, Otlu S, Çelebi Ö, Aksu P, Sağlam AG, Doğan ANC, et al. An investigation of antibacterial effects of steroids. Turk J Vet Anim Sci. 2017:41: 302-5.

31. Sen A, Dhavan P, Shukla KK, Singh S, Tejovathi G. Analysis of IR, NMR and antimicrobial activity of $\beta$-sitosterol isolated from Momordica charantia. Sci Secure J Biotechnol. 2012;1:9-13.

32. Yusuf AJ, Abdullahi MI, Aleku GA, Ibrahim IA, Alebiosu CO, Yahaya M, et al. Antimicrobial activity of stigmasterol from the stem bark of Neocarya macrophylla. JOMPED. 2018;2:1-5.

33. Sova M. Antioxidant and antimicrobial activities of cinnamic acid derivatives Mini Rev Med Chem. 2012:12:749-67.

34. Kurek A, Nadkowska P, Pliszka S, Wolska Kl. Modulation of antibiotic resistance in bacterial pathogens by oleanolic acid and ursolic acid. Phytomedicine. 2012;19:515-9.

35. Yenn TW, Khan MA, Syuhada NA, Ring LC, Ibrahim D, Tan W-N. Stigmasterol: an adjuvant for beta lactam antibiotics against beta-lactamase positive clinical isolates. Steroids. 2017:128:68-71.

36. Wagner H, Ulrich-Merzenich $\mathrm{G}$. Synergy research: approaching a new generation of phytopharmaceuticals. Phytomedicine. 2009:16:97-110.

37. Sibanda T, Okoh A. The challenges of overcoming antibiotic resistance: plant extracts as potential sources of antimicrobial and resistance modifying agents. Afr J Biotechnol. 2007;6:2886-96.

38. Catteau L, Zhu L, Van Bambeke F, Quetin-Leclercq J. Natural and hemisynthetic pentacyclic triterpenes as antimicrobials and resistance modifying agents against Staphylococcus aureus: a review. Phytochem Rev. 2018;17: 1129-63.

39. Sánchez E, Morales CR, Castillo S, Leos-Rivas C, García-Becerra L, Martínez DMO. Antibacterial and antibiofilm activity of methanolic plant extracts against nosocomial microorganisms. ECAM. 2016;2016

40. Romero CM, Vivacqua CG, Abdulhamid MB, Baigori MD, Slanis AC, Allori MCGd, et al. Biofilm inhibition activity of traditional medicinal plants from northwestern Argentina against native pathogen and environmental microorganisms. Rev Soc Bras Med Trop. 2016;49:703-12.

41. Sasirekha B, Megha D, Chandra MS, Soujanya R. Study on effect of different plant extracts on microbial biofilms. Asian J Biotechnol. 2015;7:1-12. 
42. Cheng W-J, Zhou J-W, Zhang P-P, Luo H-Z, Tang S, Li J-J, et al. Quorum sensing inhibition and tobramycin acceleration in Chromobacterium violaceum by two natural cinnamic acid derivatives. Appl Microbiol Biotechnol. 2020:1-13.

43. Da Silva GNS, Primon-Barros M, Macedo AJ, Gnoatto SCB. Triterpene derivatives as relevant scaffold for new antibiofilm drugs. Biomolecules. 2019;9:58.

44. Al-Yousef HM, Sheikh IA. $\beta$-Sitosterol derived compound from onion husks non-polar fraction reduces quorum sensing controlled virulence and biofilm production. Saudi Pharm J. 2019;27:664-72.

45. Nazzaro F, Fratianni F, De Martino L, Coppola R, De Feo V. Effect of essential oils on pathogenic bacteria. Pharmaceuticals. 2013;6:1451-74.

46. Aldred KJ, Kerns RJ, Osheroff N. Mechanism of quinolone action and resistance. Biochem. 2014;53:1565-74.

47. Brackman G, Coenye T. Quorum sensing inhibitors as anti-biofilm agents. Curr Pharm Des. 2015;21:5-11.

48. Trentin DS, Silva DB, Frasson AP, Rzhepishevska O, Da Silva MV, Pulcini EdL, et al. Natural green coating inhibits adhesion of clinically important bacteria Sci Rep 2015;5:8287

49. Musumeci R, Speciale A, Costanzo R, Annino A, Ragusa S, Rapisarda A, et al. Berberis aetnensis C. Presl. Extracts: antimicrobial properties and interaction with ciprofloxacin. Int J Antimicrob Agents. 2003:22:48-53.

50. Anokwah D, Mensah AY, Mireku EA, Danquah CA. Antimicrobial and antiinflammatory potentials of Aidia genipiflora (DC.) Dandy (Rubiaceae). Planta Med. 2019;85:258.

\section{Publisher's Note}

Springer Nature remains neutral with regard to jurisdictional claims in published maps and institutional affiliations.

\section{Submit your manuscript to a SpringerOpen ${ }^{\circ}$ journal and benefit from:}

- Convenient online submission

- Rigorous peer review

- Open access: articles freely available online

High visibility within the field

- Retaining the copyright to your article

Submit your next manuscript at $\boldsymbol{\nabla}$ springeropen.com 